\title{
Youth Culture and EFL Students' Development of Integrative Motivation
}

\author{
Ranwa Khorsheed \\ Arab International University, Syria
}

\begin{abstract}
The aim of this study is to examine the role of the habitual use of English mediums (English T.V programs and English websites), being informal learning contexts, in Syrian non-English majors university students' development of integrative motivation. Furthermore, this study aims at highlighting the importance of integrative motivation in foreign language acquisition whether for teachers, learners or language policy makers. Results showed that the students professed positive attitudes towards learning English in general and a good level of integrative motivation. Furthermore, resorting to correlational formula has proven that students' habitual use of English mediums do have a role in developing integrative motivation especially viewing English T.V programs. It was also noticed that the students' integrative motivation did have a positive influence on their achievement in the English language course. The most significant implication of this research is that once learners realize that they could use English for self expression, as a desire brought on by the impacts of the international youth culture, they will be more integratively motivated to learn the language.
\end{abstract}

Index Terms - motivation, integrative motivation, instrumental motivation, youth culture, attitudes

\section{Purpose OF Study}

The aim of this study is to examine the linguistic and cultural effects of globalization on a group of Syrian nonEnglish major university students. Mainly, it will analyse students' attraction to youth culture and its effects on their integrativeness (being a composite of integrative motivation to learn English). Thus, the study will focus on students' habitual use of English multimedia, being popular amongst youth, and its role in students' development of integrative motivation. In addition, this study will highlight the importance of integrative motivation for the students' language learning process.

Thus, this study will seek to fulfil its aim by:

1- Examining students' habitual use of English multimedia (being informal learning contexts).

2- Assessing students' integrative motivation.

3- Establishing a link between students' linguistic achievement and their integrative motivation.

\section{LITERATURE REVIEW}

\section{A. The Socio-educational Model of Gardner, 1985}

It is quite well known that the process of language learning is basically a "social event". This has been the primary reason that has led researchers to focus on the "social dimensions" that could have an effect on language learning motivation (Dornyei, 2001). Researchers have become quite aware of many issues that could be related to the area of language learning motivation. One of these important issues is that of "language globalization" (ibid). Thus, some social psychologists Like Gardner, became interested in studying the motives behind this socially originated phenomenon. Gardner's model comes as the result of a long examination of other models. Therefore, it is more refined and universal.

Gardner's model focuses on individuals' cultural and social context. This is because it was common that some English societies do not believe or encourage learning another language. In addition, it has also been notable, as Baker (1992) states, that the American community holds a philosophy of "assimilation of minority cultures and languages". This means giving a much superior status to their own language and culture over others. This could explain the spread of a global culture that basically carries the American stigma.

Gardner's model examines four major variables that represent individual differences. These variables are "language aptitude, motivation, integrativeness, and attitudes towards the learning situation". It is obvious that these variables are affected by the "cultural and social" context of individuals (Gardner, 1979).

The model distinguishes between "formal" and "informal" language acquisition contexts. The formal context is represented by a typical "class room" in which the main goal is to become fluent in the target language. Whereas the informal context is when an individual "watches a foreign film, listens to foreign radio programs", uses the internet and read English materials only for the sake of entertainment.

As stated by Gardner (1985), motivation and language aptitude have a key role in informal learning contexts in the sense that they are the factors that attract an individual to listen or watch foreign programs. However, Aptitude is not of 
main concern in the present study because as stated by Gardner (1983), it is motivation that takes over aptitude to a large extent in the learning process.

The model highlights two predicted outcomes. These are "linguistic and non linguistic" out comes (Gardner, 1985). Linguistic outcomes are exemplified by "pronunciation, vocabulary, and fluency". Non linguistic outcomes are represented by newly acquired "cultural values and beliefs, attitudes, and self-concept". These later outcomes will be the prime focus of the current research. It should be noted that linguistic outcomes in particular, keep "feeding" back into the model. In other words, watching a foreign film or listening to foreign radio programs affects motivation; which in turn affects "continual classroom experiences" and other informal learning contexts in a non ending "cycle". The following diagram is adapted from Gardner (1983), and summarizes the components of the model. (See figure 3.2).

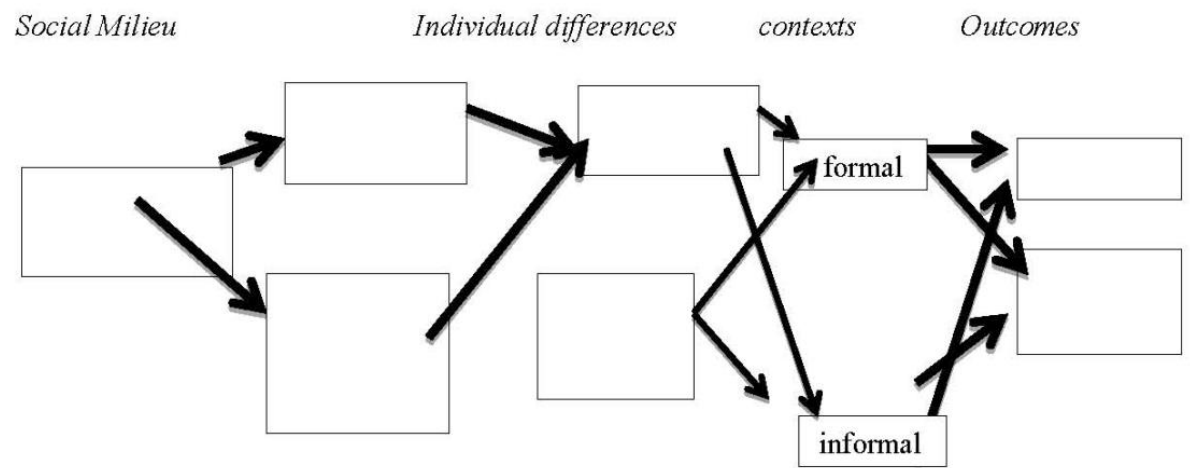

Figure 1. The socio-educational model (Gardner, 1983)

\section{B. Integrative Motivation}

Clement, Dörnye \& Noels (1994:5) define integrative motivation as the following:

A positive interpersonal/ affective disposition toward the L2 group and the desire to interact with and even become similar to valued members of that community. It implies an openness, and respect for, other cultural groups and ways of life; in the extreme, it might involve complete identification with the community (and possibly even withdrawal from one's original group). Thus a core aspect of the integrative disposition is some sort of psychological and emotional identification.

Clement ...et al (1994) seem to be concerned with the language learner's social and psychological state. This is because learners seem to be strongly affected by the target language "cultural group". Thus, they develop a need to "interact" with that group or adopt its cultural norms because of a personal attraction. These learners are most likely to put forth immersive efforts to learn the target language in order to fulfil their need and desire of integration. This state of integration could be classified into two types according to the kind of outcomes it brings about whether positive or negative. If the integration process originated from a disposition that represents "openness" and "respect" for other speech communities and their culture, then it is most likely to be a positive integration. This kind of positive integration will probably facilitate the language learning process. However, a negative integration would be represented by an over rated attraction and favourability of the target language and its culture and a "gradual withdrawal" from one's native language and its culture. In relation to these types of integration, comes the role of the youth culture which has been discussed in chapter 2 (pop culture). This role is mainly concerned with attracting youths and consequently driving them indirectly in the path of foreign language learning, namely English.

\section{Baker's Language Attitude Model, (1992)}

Baker (1992) was concerned with distinguishing the most influential variables (whether direct or indirect) on language attitudes. Thus, he proposed a model depending on an" input and output equation" of attitudes. In this equation he considers "gender, age, language background and school" as inputs while "language attitude and language ability" are considered to be outputs. Baker has exemplified his proposal of this model with the following diagram:

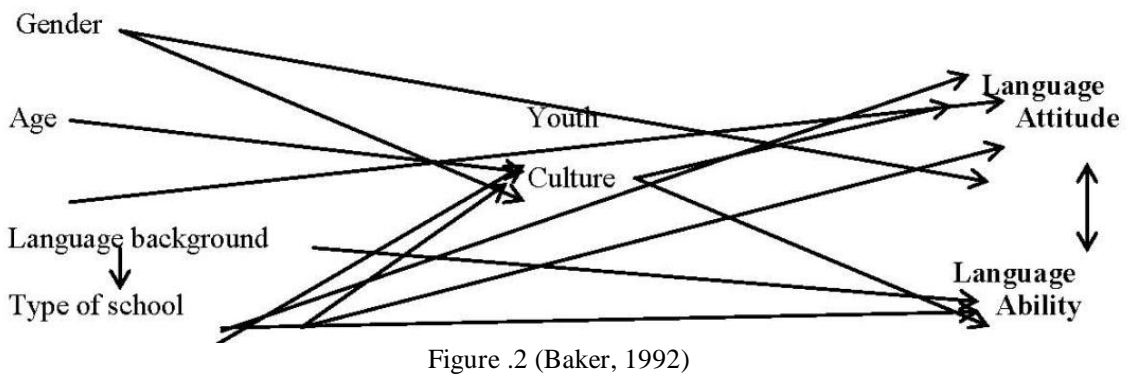


In his model, Baker (Ibid) points out a possibility of the choice of school type being influenced by the language background of the students. Consequently, the four variables (gender, Age, language background, and type of school) are most likely to affect "the kind of youth culture being experienced" i.e. whether a popular or a local culture. Indirectly and through youth culture, which has a direct effect on attitude, the above variables tend to have an influence on language attitude. Whereas, the two outputs ability and attitude have a "mutual" influence on each other. Baker describes his model as "dynamic" and evolving. He applies this description even to the two variables of gender and school choice which might be considered as fixed inputs. He explains how there are some aspects of gender, e.g. "how an individual perceives himself from a Masculine/ feminine perspective", which are considered to undergo "changes" and development constantly. The same applies to the variable of school choice. Even if the school is taken as a fixed "physical property", how a student perceives school and the experience he had are both "subjected" to change. Furthermore, youth culture is also subjected to "change" as students move on in their "teens and youth years". Eventually, the ultimate goal that Baker seeks to fulfil is to construct and present a language attitude model that reveals the major social and linguistic elements that affect and constitute attitudes.

\section{The Present Study and the Conceptual Framework}

This study has adapted a convergence of both Gardner's (1985) and Baker's (1992) models. Both models employ the elements of culture and linguistic abilities. However, Gardner's model is mostly structured on a motivational point of view with a dominant aspect of integrativeness. It analyses the factors which contribute to the formation of students' integrative motivation and the overall effects on students' second/ foreign language acquisition and achievement. On the other hand, Baker's model has youth culture as the vital centre of his model which has a great effect on another major component which is language attitudes. Although Baker's model was basically structured to study language attitudes towards indigenous and "nearly perished" languages like Wels, in contrast with other prominent and popular languages like English, this has not made it exclusive to such linguistic cases. On the contrary, Baker's model was quite useful to many researchers e.g. Dewaele (2005) and Lamb (2004) in highlighting the significant role of youth culture in the formation of language attitudes regardless of the cultural and linguistic milieu. Thus, comes the rationale for the convergence of Gardner's and Baker's models.

With regard to the present study, the international youth culture has been given a primary role. This is because it is a major element of attraction which affects youth's language attitudes, increases their integrativeness and encourages them to use English multimedia. In addition, multimedia in its turn, being a source of informal contact with English and an informal language learning context, affects language attitudes and integrative motivation. Consequently, integrative motivation influences learners' attitudes towards the English language course and thus affects their linguistic achievement.

Thus, it is evident that this research perspective of informal learning contexts runs against Gardner's proposition that considers learners' involvement in informal learning contexts as part of the entailed consequences of integrative motivation but not the cause (Gardner, 1983, 1985).

It should be noted that the current study did not include the variable of age nor type of school because all of the participants belong to the same age group and the same major (Science).

\section{RESEARCH TOOL}

The main and basic tool of the current study is a questionnaire of 93 items, 3 of which are demographic statements, No $(1,2,3)$. The rest of the items are classified into 14 scales that are intended to cover the research problem, questions and hypotheses. This questionnaire is based on the AMTB (the attitude motivation test battery) (Gardner, 1985) and on the attitude and youth culture questionnaire (Baker, 1992). However, some items have been modified according to the sociocultural context of the study. In addition, items regarding (reading habits) were omitted due to proficiency reasons. It should also be noted that the questionnaire was conducted in Arabic (the students' native language), in order to avoid any incidents of miscomprehension.

\section{The Construction of the Questionnaire}

The questionnaire consists of two parts. The first part is related to demographic information (gender, age, academic year, and parents' educational level). The second part of the questionnaire consists of the following 14 measurement scales. It is important to note that the word "foreign" in the questionnaire was explained to the participants as another equivalent to "English".

1- Attitudes towards native speakers of English: this scale consists of 9 statements (items: 4-12).

It assesses students' attitudes towards native speakers of English from different perspectives

e.g. sociability, humour, sophistication, respectability and superiority.

2- The effect of interaction with native speakers of English: 1statement (item: 13).

3-English T.V programs viewing: 4 statements (items: 14-17). This scale evaluates the preference of English programs over others taking into consideration certain kinds of English programs. In addition, it assesses the frequency at which the viewing habit takes place.

4-Attachment to English T.V programs: 3statements (items: 18-20). This scale evaluates the reasons that make viewers attached to English T.V programs. 
5-Effects of watching English T.V programs: 3 statements (items: 21-23). This scale evaluates the societal, psychological and linguistic motivational effects that English T.V programs have on their viewers.

6-Internet use: 5 statements (items: 24-28). This scale evaluates the preference of English websites over others with regard to certain kinds of websites and the suitability of English s a major language used on websites. In addition, it assesses the frequency of usage.

7- Fashion \& western culture: 2 statements (items: 29-30). This scale evaluates students' interest in keeping up to date with the latest western fashion and their desire to practice some western cultural habits.

8- Personal perceptions towards learning English: 9 statements (items: 31-39). This scale evaluates students' beliefs and gains from learning English with regard to the following points: acquiring a respectable educated and distinguished self image, being able to socialize in western cultural events, and personal satisfaction.

9- Instrumental motivation: 11 statements (items: 40-49). This scale evaluates students' perspectives

about the need to learn English with regard to the following points: peers' influence, enjoy ability of the learning experience, and sociable and academic benefits.

10- Attitudes towards learning English: 4 statements (items: 50-54). This scale assesses the feasibility of the learning process, the priority of the English subject in comparison with other subjects, and students' desire to further their English skills even after graduation.

11- Attitudes towards the status of English in the world: 6 statements (items: 55-61). This scale evaluates students' attitudes towards English as a language with regard to its significant role in social communication, developments, and scientific discoveries.

12-Attitudes towards the required English language course: 6 statements (items: 62-67). This scale evaluates students' perceptions towards the required English course with regard to its importance, clarity, excitement and the required effort to study it.

13-practical steps of improvement (motivational intensity): 12 statements (items: 68-79). This scale assesses students' actual behaviour while aiming at improving their level of linguistic proficiency. In the current questionnaire, the students' acts of improvement were represented as follows: talking to foreigners whenever possible, classroom participation, joining extra curricula activities, doing homework and studying regularly, and asking the teacher when in need.

14- Uses of English: 14 statements (items: 80- 93). This scale assesses students' frequency and attitudes toward the use of English in different circumstances e.g. with friends, family, in class, self expression, shopping, speaking of science and inventions.

This questionnaire depended on a five point likert scale to measure responses limits according to the following table:

\begin{tabular}{|c|c|c|c|c|c|}
\hline & & & & & Ct \\
\hline Response & Strongly agree & Agree & Neutral & Disagree & Strongly disagree \\
\hline Degree & 5 & 4 & 3 & 2 & 1 \\
\hline Limits & $4.2 \_<$ & 3.4 & 2.6 & 1.8 & 1 \\
\hline
\end{tabular}

The questionnaire was statistically analysed using the SPSS program. It has proven to be valid, when reviewed by specialists. This is because it fulfils the research aims, answers the research questions from a statistical descriptive point, and endorses the hypotheses. These points will be clearly notable in the final chapter. In addition, the questionnaire was also proved to be reliable with a total Cronbach's alpha value of 0.835 . Thus, the questionnaire is said to have an internal consistency and homogeneity amongst the scales and each scale is said to consist of homogeneous clusters of items.

\section{PARTICIPANTS}

The participants are a group of 88 second year students at the faculty of Science -Damascus University. These students belong to the age group of (19 to 21) years old. There are two main reasons behind the choice of such a group of participants. First, these students were chosen from the faculty of science because it is almost factual that students of this faculty have a general average level of English. Second, the reason why the selected group happened to be at the second academic year is to eliminate any other factors that may affect students' perceptions. If the selected group happened to be of first year students, there is a chance of adjustment issues interference being freshmen students. Consequently, this might have certain effects on students' opinions. As for not choosing third or fourth year students, it is because these students will be attending more specialized and complicated courses of English.

The total selected group is divided into two independent sub- groups. The first sub-group consists of 30 male students, with a percentage of $36.1 \%$ of the total group. The second sub-group consists of 53 female students, with a percentage of $63.9 \%$ of the total group. There is a missing value of 5 students who didn't specify their gender, with a percentage of $5.7 \%$. The following diagram represents the total group of participants classified according to gender. 


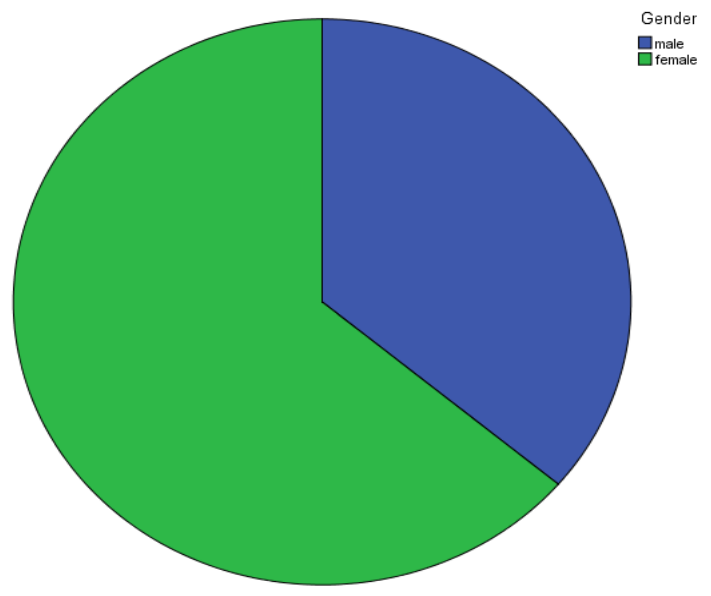

Figure.3

TABLE II.

SAMPLE'S GENDER PERCENTAGES

\begin{tabular}{|ll|c|c|c|c|}
\hline & & Frequency & Percent & Valid Percent & Cumulative Percent \\
\hline \multirow{3}{*}{ Valid } & Male & 30 & 34.1 & 36.1 & 36.1 \\
& Female & 53 & 60.2 & 63.9 & 100.0 \\
Missing & Total & 83 & 94.3 & 100.0 & \\
Total &. & 5 & 5.7 & & \\
\hline
\end{tabular}

\section{Analysis of Measurement Scales}

Each measurement scale as a whole, is considered an independent variable. This could be explained by the fact that each scale tend to represent the participants' independent personal opinions. As for the dependent variables, this questionnaire has presented a single dependent variable which is the required English language course. The results obtained from each measurement scale will be presented and discussed in the following sections.

\section{A. Attitudes to Native Speakers of English}

Students' attitudes towards native speakers of English are said to be concerned with different aspects of native speakers' characters, e.g. social and practical sides. Thus, results showed that the students have feelings of respect for native speakers of English, with a percentage of 30.7\%. The students also agreed that native speakers of English have a good sense of humour with a percentage of $28.4 \%$; and a kind and sociable nature with a percentage of $20 \%$. In addition, $48,9 \%$ of the students agreed that native speakers of English are educated. Furthermore, the students professed their admiration of native speakers of English with a percentage of 20.5\%. Moreover, $29.1 \%$ of the students agreed that native speakers of English are sophisticated. Consequently, 38.6\% exhibited a desire to meet -get acquainted- with native speakers of English. However, 33.7\% didn't associate any superiority with the English speaking communities over speakers of other languages. Finally, an overall evaluation of the statistical analysis of this measurement scale showed that the students in general have positive feelings towards native speakers of English with a percentage of 34.42\% (Mean:3.02/SD: 0.84).

\section{B. The Effect of Interaction with Native Speakers of English}

The results confirmed the positive effect that interaction with native speakers of English might have on the students. With a percentage of $46 \%$, the results showed that the students strongly agreed that the more English speaking people they knew, the more their desire to learn English increased. This measurement scale has a mean value of 4.25 and a standard deviation value of 0.90 .

\section{English T.V Programs Viewing}

Results showed that $46 \%$ of the students strongly agreed that they prefer watching English T.V programs to others (Mean:3.32/SD:1.29). As for the frequency of the students' viewing activity, the results presented a variety of the students' viewing habits: daily viewing $23 \%$, every other day $26.4 \%$, monthly $23 \%$, and never $21.8 \%$. The students who professed a daily habit of watching English T.V programs exhibited different lengths of viewing time (49.1\% spend 1 hour, $36,8 \%$ spend 2 hours, $1.8 \%$ spend 3 hours, $5.3 \%$ spend 4 hours, $7 \%$ spend more than 4 hours).

With regard to the most preferred type of English T.V programs, statistical analysis presented the following results:

$48.8 \%$ of the sample preferred watching English films, $23.8 \%$ preferred cultural programs, $10.7 \%$ preferred English songs and $6 \%$ preferred English series. Thus, the most popular type of English Programs, is films. 


\section{Attachment to English T.V Programs}

Many reasons have been found to justify the sample's attachment to English T.V programs. These reasons had the following percentages:

$46.6 \%$ of the students agreed that they like English T.V programs because they represent a source of inspiration and offer new visions and ideas. $26.1 \%$ of the students agreed that some of the English T.V programs characters help them create an attachment to these programs. In addition, $34.5 \%$ of the students stated that they like English T.V programs because of their exciting and influential stories. In general, $35.74 \%$ of the students agreed that they are attached to English T.V programs because of the novelty of their ideas and attractive characters (Mean: 3.45/SD:0.82).

\section{E. Effects of English T.V Programs}

English T.V programs have proven to have many effects on their habitual viewers. These effects appear to be mostly positive when considered from the participants' perspective.

$20.5 \%$ of the sample group agreed that the act of watching English programs makes them feel excited and attracted to the foreign life style. $10.5 \%$ of the sample agreed that watching English programs makes them forget about their personal problems. $43 \%$ of the sample strongly agreed that watching English programs makes them love the English language and motivates them to learn it. In conclusion, $22.3 \%$ of the students agreed that watching English programs have positive effects on their lives (Mean:3.03/SD:0.86).

\section{F. Internet Use}

The students showed a good degree of preference for English websites over Arabic ones with a percentage of 30\%. It is also worth mentioning, that about $60.2 \%$ of the students agreed that English is the most suitable language for internet websites. In addition, the students exhibited different habits of internet use according to the frequency of usage and the periods of time spent. As it was noted, $26.5 \%$ of the students use the internet on a daily basis, $6 \%$ use the internet every other day, $21.7 \%$ tend to have a weekly usage, $13.3 \%$ have a monthly usage, and $32.5 \%$ of the students did not profess any internet usage. The most important usage rates, are those pertaining to daily and weekly usage. Furthermore, it turned out that those who stated a daily usage of the internet, spend different periods of time according to the following percentages: $16 \%$ for one hour of usage, $7.4 \%$ for 2 hours of usage, and $1.2 \%$ for more than 3 hours of usage.

As for the types of preferred websites, the following results were obtained: $61.1 \%$ of the students preferred scientific websites, $15.3 \%$ preferred entertainment websites, $12.5 \%$ preferred using email services, $6.9 \%$ preferred using general knowledge websites, and $4.2 \%$ preferred using chat services.

Students' significant preference of scientific websites is due to their academic major.

\section{G. Fashion and Culture}

The students' involvement in the international youth culture, could be detected in their attraction to trends, inventions, and western cultural norms. This is more properly stated by the following percentages: $37.9 \%$ of the students are keen on keeping up with the latest foreign trends and inventions. In addition, $19.5 \%$ of the students agreed that they like practicing in some foreign cultural norms and habits. In conclusion, $28.73 \%$ of the participants showed a preference for foreign trends and cultural norms (Mean:3.02/SD:0.91).

\section{H. Personal Perceptions towards Learning English}

Results analysis has yielded a variety of the students' perceptions towards learning English, with regard to the different effects it has on their personalities as individuals. These are represented by the following percentages:

$27.9 \%$ of the participants agreed that learning English makes them more respectable by others. $50 \%$ of the students strongly agreed that being familiar with two languages makes them a better person. In addition, $83.9 \%$ of the students agreed that learning English makes them feel more educated. 24.4\% of the students stated that learning English makes them able to participate in foreign cultural customs and traditions. Furthermore, $72.7 \%$ agreed that learning English makes them feel special.

65.9\% stated that learning English gives them self satisfaction. 53.16\% of the students agreed that learning English elevates their consciousness. Moreover, 51.6\% agreed that learning English makes them feel more civilized. 31.8\% of the students said that learning English gives them a sense of renovation. All in all, 36.53\% of the students agreed that learning English has positive influences on them as individuals (Mean: 3.59/SD:0.53).

\section{Instrumental Motives for Learning English}

The participants showed different instrumental reasons for learning English as apparent in the following percentages:

49.4\% of the students agreed that learning English is an exciting experience. 36.15\% agreed that learning English is sufficient enough not to learn other languages. $67.1 \%$ agreed that learning English will be the key to expand their knowledge and scientific resources. In addition, $48.14 \%$ agreed that learning English will make them more appreciative of western art and literature. 81.6\% agreed that learning English will facilitate any transactions with foreigners. In conclusion, $75 \%$ of the students seem to exhibit a high level of instrumental motives to learn English (Mean:2.19/SD:0.38). 
The students exhibited different attitudes concerning learning English as presented in the following percentages:

$39.5 \%$ of the students agreed that learning new skills in English is a difficult task. 35.2\% agreed that studying the main courses, which are more related to their major, has more priority when compared to studying for the English language course. In addition, 51,2\% strongly confirmed their will to further take and improve their English language learning even after graduation. In general, $60.64 \%$ of the students appeared to have positive attitudes towards English (Mean:3.22/SD:0.49).

\section{K. Attitudes towards the Status of English}

With regard to the students' attitudes towards the status of the English language, the following results were obtained:

$48.9 \%$ of the students agreed that English is the most important language in the world. 33.14\% greed that English is a must for countries' development. Furthermore, 20.9\% agreed that English is a sophisticated language and reigns supreme in the world. $25 \%$ agreed that English must spread -reach- to all of the societies in the world. In addition, $37.6 \%$ agreed that English is the language of science and discovery. $46.16 \%$ agreed that English is a rich language. $22.6 \%$ showed their favourability of English being the primary language of the world. In general, $37.64 \%$ of the sample had positive attitudes towards the present status of the English language (Mean:2.94/SD:0.07).

\section{Attitudes towards the English Language Course}

The students' attitudes towards their English language course varied according to the following percentages:

$67.9 \%$ of the students agreed that the English language course is one of the basic and important subjects of the curricula. $66.6 \%$ agreed that the contents of the course are good and useful. In addition, 38.15\% agreed that the course contents are exciting and interesting. 45.4\% approved of the course contents clarity; while $33.14 \%$ agreed that the course contents are complicated. $71.13 \%$ agreed to the efforts required to study and pass the English language course. Finally, this measurement scale had a general mean value of 3, 44 and a standard deviation value of 0.05 .

\section{Practical Steps of Improvement (Motivational Intensity)}

There are many practical steps that could enhance the students' level of proficiency. The percentages of the students which have an actual application of these steps, are presented as follows:

$76.8 \%$ of the students confirmed their will to use English to communicate with foreign neighbours. $45.8 \%$ confirmed their regular participation in the English language lecture. In addition, 51.7\% stated their will to join an English language club if it was available at their faculty. 52.9\% confirmed doing their English assignments with care and attention. $74.13 \%$ confirmed that they are keen on correcting any mistakes in their English assignments. Furthermore, $68,6 \%$ stated their habit of asking the course instructor when facing any difficulty. $44.8 \%$ confirmed doing extra curricula activities in relation to the English language course. $17.14 \%$ agreed that they study only in amounts that enable them to pass the subject. Moreover, $71.7 \%$ stated that they study in amounts that enable them to pass with high marks. $14.9 \%$ agreed that they depend on luck to pass the English subject.

$63.9 \%$ confirmed doing regular revisions of their English lessons. In conclusion, $49.26 \%$ of the students appeared to apply practical steps of improvement to enhance their English language proficiency (Mean:3.26/SD:0.37).

\section{N. Use of English}

The results showed different percentages of the students' views towards using the English language in their lives. These percentages are presented as follows:

$61.13 \%$ of the students stated their acceptance of using English in their daily lives along with Arabic. $25.6 \%$ confirmed using English with their friends. In addition, 23.14\% confirmed using English with their family. 48.14\% stated their use of English only in the classroom. 30.6\% of the students only use English when travelling. Furthermore, $34.13 \%$ use English when discussing scientific issues and inventions. 19.8\% stated their use of English to express themselves. 26.4\% confirmed their use of English when lacking the courage to say something. Moreover, $17.9 \%$ confirmed their use of English while shopping. 32.10\% agreed that using English makes them more sophisticated. 25.12\% agreed that using English makes feel more like in a western atmosphere. However, $30.9 \%$ stated their preference to use the language of the visited country rather than English. Thus, 31.24\% of the students appear to have positive attitudes towards the use of English in their lives (Mean:2.80/SD:0.05).

\section{O. Gender Differences}

Depending on the $\mathrm{t}$ - test, analysis showed that there is no difference between males and females attitudes. This result is ascertained by the $t$ - test value which is 0.067 . Since this value is higher than 0.05 , then it approves the above mentioned result. Using the F-test -one way Anova-, with a value of $0.286>0.05$, results showed that there is no difference between the participants' attitudes in relation to their fathers' level of education. In addition, the F- test- with a value of $0.708>0.05$ - also proved that there is no difference between the participants' attitudes in relation to their mothers' level of education.

\section{Possible Correlations amongst Measurement SCAles}


Using" Pearson" correlation formula amongst the questionnaire's items and sections, some major correlations were discovered. These relations will be detailed in the coming sections.

A. Correlations of Attitudes towards the Status of English

According to data analysis, students attitudes towards the status of English showed some significant correlations as presented in the following table:

TABLE III

\begin{tabular}{lll}
\hline Scale & sig & r \\
\hline Attitude to native speakers of English & 0.21 \\
Attitudes to the English language course & 0.333 \\
Practical steps of improvement & 0.303 \\
Use of English & 0.420 \\
Effects of English T.V programs & 0.521 \\
Interaction with native speakers of English & 0.006 \\
\hline
\end{tabular}

The highest correlation value was with the (use of English) scale. This might indicate, that the higher the status the learners ascribe to the English language, the more frequent their use of the language becomes.

\section{B. Correlations of Internet Use}

There is a correlation between participants' use of the internet and other measurement scales of the questionnaire as shown in the following table:

TABLE IV

\begin{tabular}{lll}
\hline Scale & sig & r \\
\hline Attitudes towards native speakers of English & 0.006 & 0.347 \\
Personal perceptions towards learning English & 0.251 \\
Attitudes towards the status of English & 0.024 & 0.376 \\
\hline
\end{tabular}

As it is shown above, the highest correlation value is that with the students' attitudes towards the status of English scale. This might indicate that the more the students use the internet (English websites), the more positive their attitudes get. On the other hand, the lowest correlation is that with the scale which measures personal perceptions towards learning English.

\section{Correlations of Personal Perceptions towards the Learning of English}

Analysis has proved an existing correlation between students' personal perceptions towards the learning of English and other scales as shown in the table below:

TABLE V

\begin{tabular}{|c|c|c|}
\hline Scale & $\mathbf{r}$ & sig \\
\hline Attitudes towards native speakers of English & 0.255 & 0.02 \\
\hline Internet use & 0.251 & 0.024 \\
\hline Fashion & 0.254 & 0.023 \\
\hline Interaction with native speakers of English & 0.377 & 0.00 \\
\hline The status of English & 0.534 & 0.0 \\
\hline Instrumental motives & 0.255 & 0.20 \\
\hline Practical steps( motivational intensity) & 0.309 & 0.005 \\
\hline
\end{tabular}

Analysis has revealed that the highest correlation value is that with the scale that measures students' attitudes towards the status of English. However, the lowest correlation was with the English and internet usage scale. Thus, it could be said that the higher the status the students assign with English, the more positive their personal perceptions get towards the learning of English.

\section{Correlations of attitudes towards Native Speakers of English}

The students' attitudes toward the Western society have shown positive correlations with some measurement scales as presented in the table:

TABLE VI

\begin{tabular}{lll}
\hline Scale & sig & r \\
\hline Interaction with native speakers of English & 0.293 \\
Effects of English T.V programs. & 0.006 \\
Attachment to English T.V programs & 0.577 \\
English and the internet & 0.488 \\
Fashion & 0.0 & 0.266 \\
Watching English programs & 0.013 & 0.357 \\
\hline
\end{tabular}

The highest two correlations are those with the scales which measure effects of English T.V programs and attachment to English T.V programs. Therefore, it could be concluded that the more the students are attached and 
affected by English T.V programs, the more positive their attitudes get towards the western society. It is worth adding that the most influential types of English programs are those of films (mean:3.64/SD:0.63) and series (mean:3.77/SD:0.66). On the other hand, the least influential type is that of pure cultural programs (mean:3.24/SD:0.58). English Films and series tend to have quite an impact on the participants' attitudes towards the western society more than pure cultural programs. This could be explained by the fact that implicit cultural messages are more influential than those who are explicit as mentioned in chapter (2).

E. Correlations of Interaction with Native Speakers of English

Interaction with native speakers of English has shown some correlations with other scales as displayed in the table:

TABLE VII

\begin{tabular}{|c|c|c|}
\hline Measurement & $\mathbf{r}$ & sig \\
\hline Motivational intensity & 0.237 & 0.029 \\
\hline Use of English & 0.339 & 0.001 \\
\hline Effects of English T.V programs & 0.275 & 0.01 \\
\hline Attitudes towards native speakers of English & 0.389 & 0.0 \\
\hline
\end{tabular}

As presented in the table, the highest correlation value is with the scale which measures attitudes towards native speakers of English. It might be concluded that the more frequent the interaction with native speakers of English is, the more positive the attitudes get.

\section{F. Correlations of Attitudes towards the English Language Course}

Attitudes towards the English language course have correlations mainly with the motivational intensity scale and the scale which measures English T.V programs effects. This might be summed up by the fact that positive attitudes towards the English course would eventually lead to a more intensive state of motivation in order to achieve a desired level of proficiency. As for the effects of English T.V programs; they are mainly represented by developing a desire to learn the language of these programs (English) and fostering positive attitudes toward the required English language course. These effects are represented in the following table:

TABLE VIII

\begin{tabular}{llr}
\hline Scale & r & sig \\
\hline Motivational intensity & 0.327 & 0.002 \\
Effects of foreign T.V programs & 0.228 & 0.043 \\
\hline
\end{tabular}

\section{G. Correlations of Motivational Intensity}

Motivational intensity (practical steps of improvement) has shown a high correlation value with the language usage scale, as presented in the table.

\begin{tabular}{lll} 
& TABLE IX & \\
\hline Scale & R & sig \\
\hline Use of English & 0.359 & 0.001 \\
\hline
\end{tabular}

This high correlational value could mean that the more intensive the students' motivation is, the more frequent their language usage gets.

\section{H. Correlations of English T.V Programs' Effects}

English T.V programs effect has shown some correlations with a number of scales. The highest correlational value was with the scale that measures attachment to English T.V programs as presented in the table.

TABLE X

\begin{tabular}{llc}
\hline Scale & sig & r \\
\hline Use of English & 0.313 & 0.003 \\
Attitudes towards native speakers of English & 0.341 \\
Attachment to English T.V programs & 0.001 & 0.555 \\
\hline
\end{tabular}

Thus, it could be concluded that the greater the attachment, the higher the effects.

\section{Correlations of the Use of English}

The language use scale has many correlations with other scales. However, the highest correlation value was with the scale that measures fashion and cultural attachment. This means that the increase in the rate of the language use tends to occur whenever the students express or show a high degree of attachment or involvement in western cultural activities, occasions, and the latest fashionable trends. This could mainly be due to the existence and spread of youth culture which encompasses all sorts of trends and fashion that attracts young people. This could explain the low correlation value of instrumental motivation which gives support to the research hypothesis that the students are being more culturally and integratively oriented. Correlational values are presented in the following table: 
TABLE XI

\begin{tabular}{lll} 
& TABLE XI & \\
\hline Scale & sig & \\
\hline Attitudes towards native speakers of English & 0.01 \\
Attachment to English programs & 0.274 \\
English and the internet & 0.299 \\
Fashion \& culture & 0.265 \\
Instrumental motivation & 0.014 & 0.470 \\
\end{tabular}

\section{J. Correlations of Fashion and Culture}

The measurement scale of fashion and culture has four correlation values. However, the highest value is that with the status of English scale. This means the more the students are culturally immersed the more they ascribe a high status to the English language.

TABLE XII

\begin{tabular}{lrr}
\hline Scale & sig & r \\
\hline Personal perceptions of language learning & 0.254 \\
Instrumental motivation & 0.023 & 0.280 \\
The status of English & 0.347 \\
English programs effects & 0.002 & 0.260 \\
\hline
\end{tabular}

\section{Conclusions Concerning MeAsurement Scales Correlations}

The most significant correlation values amongst measurement scales are those related to students' habit of watching English T.V programs, their attitudes to native speakers of English, and the fashion and cultural attraction.

It was perceived that the degree of students' attachment to English T.V programs, controls to a great extent the amount of affect those programs might produce. The most prominent effects of watching English T.V programs and developing a strong attachment to them, are those pertaining to the students' attitudes towards native speakers of English and their attitudes toward the status of the English language. Watching English programs, is most likely to make the students develop positive attitudes and attraction towards western societies. In addition, it increases their appreciation of English being the language of global communication.

It was also discovered that students' positive attitudes towards the status of English have many effects. They affect students' personal perceptions towards learning the language, the intensity of their motivation, and the frequency of using the language in their daily lives as they find it more prestigious. Furthermore, this has made their attitudes and evaluation of native speakers of English more positive.

\section{INTEGRATIVE MOTIVATION}

Gardner $(1985,2000)$ had identified three main components for integrative motivation: Integrativeness, attitudes towards the learning situation, and motivation. The participants' integrative motivation was calculated with regard to the above mentioned sub-scales which constitute of the questionnaire's items:

It should be noted that the items chosen for each scale are similar to those of Gardner's (1985).

A-Integrativeness:

1-Attitudes towards the target language group: (Items: 4-13). Mean: 3.37> 3 /SD: 0.617 (good).

2-Interest in foreign languages: (Items: 42-53-92-93). Mean: 3.21>3 / SD: 0.517. (good)

3-Integrative orientation: (Items: 34-47-49-50). Mean: 3.56>3.4 / SD: 0.704. (good).

The total score of integrativeness: Mean: 3.45>3.4 / SD: 0.38. (good).

B-Attitude toward the learning situation:

It is basically restricted in this research to the evaluation of the course. This includes (items 62-67), Mean: $3.42>3.4 /$ SD: 0.479. (positively strong).

C-Motivation:

1- Motivational intensity: (Items 68-79). Mean: 3.22>3/ SD: 0.38 (good).

2- $\quad$ Attitude toward learning the target language: (Items 31-33-35-41-43-44-46-48-52)

Mean: 3.11>3 / SD: 0.401. (Positive attitudes).

3- Desire to learn the target language: (Items: 40-54-74) .Mean: 3.84>3.4 / SD: 0.79 (Strong desire)

The total score of Motivation: Mean: 3.39>3,4 / SD: 0.41 (good).

The sum of integrative motivation: Mean: $3.42>3,4$ / SD: 0.32 (good).

After calculating the sum of the three measures that comprise integrative motivation, the scale had a value of 3.42> 3.4 which is considerably good.

The following diagram, ( figure 4) represents the students' integrative motivation : 


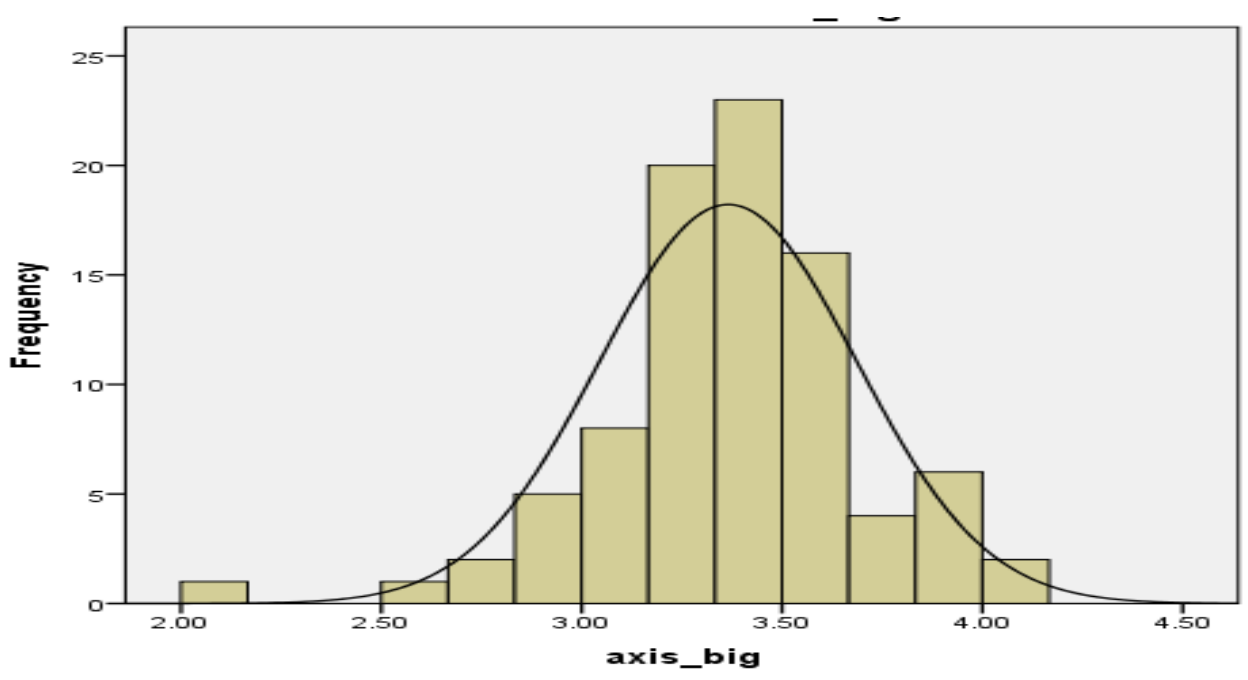

Figure.4. Integrative motivation

The horizontal axis represents the values of students' integrative motivation; whereas the vertical axis represents the number of students matches each of the values.

\section{CONCLUSIONS}

There are many conclusions could be drawn concerning the state of the students representing the sample group. These students are said to mostly show a great desire to learn English along with a good degree of integrativeness. This has been exemplified by their attraction towards western societies in general and English speaking communities in specific. What has helped in the creation of this integrativeness, is the students' attraction to the international youth culture, which adopts English as its language of communication and which has been representing "the most meaningful contact with the language" (Cheung,2001) cited in (Lamb,2004) . In addition, the students had managed to have a good degree of familiarity with the target group. Thus, they have created some integrative orientations (Clement \& Kruidenier, 1983). This sense of familiarity and feelings of belonging to a greater cultural frame of reference, the international popular culture, have emerged as a result of the students' contact and use of English media. This contact has broadened their perspectives and made them more conscious about the world around them (Arnett, 2002).

It was noted that the major factor that has strengthened the degree of the students' integrativeness was watching English T.V programs and English films in particular. Most Arab youth could be at a critical stage of their personality formation and this is where media plays its part at large. Media materials, especially English T.V programs, are constantly supplying its viewers with a diverse set of life styles (mostly American) (Erling, 2001).

Thus, media has a huge role in the formation of youths' identities (Giles, 2003). Consequently, youths select and adopt what's easy, fast, simple, entertaining, trendy, goes along with their laziness and is largely promoted by western media (Al Ayid, 2004). It could also be said that part of the students' possible and ideal selves, was present in the recreated realities of English films' stories (Higgins, 1987), (Shanahan.1999), (Arnett, 2002). Regular viewing of these films, have made these students attached to their characters and the represented foreign life styles (Da'asa, 2002). As if those students have projected their own aspirations and wishes on these episodic glimpses of the western life style; which has almost become international due to its popularity (Ibid). This issue has been thoroughly discussed in chapter 2 (p: 29), while discussing media attachment theories, with special reference to the value expectancy theory. Consequently, such attachment to English T.V programs has increased the students' motivation to learn the English language.

\section{IMPLICATIONS}

The outcomes of the current research, are of a high importance for educators, language policy makers and media institutions (Erling, 2001). As for educators and language teachers, this research will highlight the role of habitual use of English mediums on language learners' motivation and cultural integrativeness.

This study requires a comprehensive plan that focuses on how to utilize and direct language learners' habitual media use to enhance the language learning process. This plan could be derived and structured with regard to the current research hypotheses. The present research results have explained the existence of 3 types (groups of classification) of Syrian university students.

The first type is represented by heavily English media users. This group is said to show a good degree of xenophilia or xenophilic attitudes. These attitudes are explained as "the absence of ethnocentrism and authoritarianism", which the current research has measured when assessing student's interest in foreign languages as one composite of integrativeness (Gardner, 2007), (Masgoret \& Gardner, 2003). This almost addicted like use is reflected in the students' 
high level of linguistic proficiency. However, these students are most likely to be inflicted with a cultural and linguistic "anomie" (Ibid). The role of educators here is to guide those students to a moderate use of media which will lessen the negative effects and consequences.

The second type of students, is represented by those who exhibit an acceptable level of media use and a good level of English proficiency. This group might not be of major concern for teachers or educators, since it is considered to be normal and acceptable.

The third type of students is represented by those who reject any kind of English media use and who exhibit a low level of English proficiency. This group might have a high degree of ethnocentrism or authoritarianism (Ibid). The responsibility of educators in this case, is to explain the linguistic benefits of English mediums and to encourage a moderate and organized use of English multimedia.

It is worth adding, when referring to the researcher's experience as a language instructor, that there is a chance of an existence of a fourth type of students. This type might probably have a high degree of foreign cultural integration due to its heavy use of English multimedia. However, this cultural integration did not bring on any linguistic achievements. The task of teachers here, is to direct the students' cultural integration and employ it to elevate their linguistic proficiency.

With regard to the later two groups, language policy makers and media institutions hold a responsibility of making a balance between the proliferation of foreign languages in Syria and the status of the native language (Arabic). This should be done, with a little more stress and weight in the behalf of the native language. Language policy makers should have an effect on the educational systems, by setting the standards for proper implementation of foreign languages in schools and universities' curricula. In addition, language policy makers should have a role in choosing the language used by national T.V networks.

\section{LiMitATIONS AND SUGGESTIONS}

As it is known for most researches, the bigger the sample, the more significant and representative the results become. The current research was conducted on an acceptable number of students, 88 students at the faculty of scienceDamascus University. However, it might have been more representative to add other sample groups from other scientific faculties. Another thing which might have added value to the research, is including samples from literary faculties and comparing the results with those of the scientific ones. Furthermore, this study might have yielded different results if it was applied on private universities which adopt an English based curriculum regardless of the specialized majors. It is also possible to apply the same study on English majors, which might bring about different results. Furthermore, using an open ended questionnaire would introduce a good variety of responses and results. It would also add a more personal aspect to the research.

\section{REFERENCES}

[1] Arsenian, S. (1945). Bilingualism in the post-war world. Psychological Bulletin, 42, 65-86.

[2] Baker, C. (1992). Attitudes and Language. UK. Multilingual Matters.

[3] Bergh, H.V., Kuhlemeier, H., \& Melse, L. (1996). Attitudes and achievements in the first Year of German language instruction in Dutch secondary education. The Modern Language Journal. 80, 494-508.

[4] Carroll, J.B. \& Sapon, S. (1959). Modern Language Aptitude Test: MLAT. New York: Psychological corporation.

[5] Clement, R., Dornyei, Z, \&Noels, K. (1994). Motivation, self-confidence, and group Cohesion in the foreign language classroom. Language learning 44, 417 - 448.

[6] Cooper, R.L. (Ed.) (1982). Language Spread: Studies in Diffusion and social change. Indiana: Indiana University press for the Centre of Applied Linguistics.

[7] De beaugrande, R. (1991). Linguistic theory. Longman.UK.

[8] Dewaele, J.M. (2005). Socio demographic, psychological and politico cultural correlates In Flemish students' attitudes towards French and English. Journal of multilingual and multicultural development. 26 (2), pp 30-45.

[9] Dewitt, P.E. (1994). Electronic super high way. In Jackson, R.M. Global issues. UK McGraw Hill.

[10] Dornyei, Z. (2001). Attitudes, orientations, and motivations in language learning: Advances in theory, research and applications. University of Nottingham, United Kingdom.

[11] Dornyei, Z. (2005). The psychology of the language learner: Individual differences in second Language acquisition. Mahwah, NJ: Lawrence Erlbaum.

[12] Dornyei, Z., Csizer, K., \& Nemeth, N. (2006). Motivation, language attitudes and Globalization: A Hungarian perspective. Cleveland, Buffalo, Toronto: Multilingual Matters LTD.

[13] Dornyei, Z., and K. Csizer. (2002). Some dynamics of language attitudes and motivation: Results of a longitudinal nationwide survey. Applied Linguistics, 23, 421-462.

[14] Dulay, H., Burt, M. \& Krashen, S. (1982). Language two. New York: Oxford University Press.

[15] Dunkel, H. B. (1948). Second language learning. Boston: Ginn.

[16] Erling, E. J. (2001). Globalization, English, and the German university classroom: a sociolinguistic profile of students of English at the Freie Universitat Berlin. Thesis presented for the degree of doctor of philosophy, University of Edinburgh.

[17] Ervin, S. (1954). Identification and bilingualism. Harvard University (Mimeo).

[18] Gardner, R. C., \& Lambert, W.E. (1959). Motivational variables in second language acquisition. Canadian Journal of Psychology, 13, 266-272. 
[19] Gardner, R, C. (1960). Motivational variables in second language acquisition. Un published doctoral dissertation, Mc Gill University, Montreal.

[20] Gardner, R. C., \& Lambert, W.E. (1972). Attitudes and motivation in second-language Learning. Rowley, MA: Newbury House.

[21] Gardner, R. C., Smythe, P.C., \& Smythe, C. L. (1974). The Language Research Group cross national survey: Normative data, 1973-74 (Research Bulletin No. 3). London, Ontario: University of Western Ontario, Department of Psychology.

[22] Gardner, R. C., \& Smythe, P.C. (1981). On the development of the Attitude/Motivation Test Battery. Canadian Modern Language Review, 37, 510-525.

[23] Gardner, R. C. (1983). Learning another language: a true social psychological experiment. Journal of language and social psychology, 2, 3, 219-240.

[24] Gardner, R. C. (1985). Social Psychology and social language learning: the role of Attitudes and motivation. Great Britain: Edward Arnold.

[25] Gardner, R. C. (1999). Correlation, causation, motivation and second language acquisition. Canadian Psychology, 41: 1, $10-24$.

[26] Gardner, R. C. (2001). Integrative motivation: Past, present and future. University of Western Ontario.

[27] Gardner, R. C. (2007). Motivation and second language acquisition. Porta linguarum, 8, 9-20.

[28] Graddol, D. (1997). The future of English: A guide to forecasting the popularity of English in the $21^{\text {st }}$ century. London: The British Council.

[29] Higgens, E. T. (1987). Self- discrepancy: A theory relating self and affect. Psychological Review, 94,319-340.

[30] Hoffman, E. (1989). Lost in translation: A life in a New Language. New York: Dutton.

[31] Jacobsen, M. \& Imhoof, M. (1974). Predicting success in learning a second language. Modern language Journal 58, $329-36$.

[32] Kramsch, C. (2001). Beyond the second vs foreign language dichotomy: The subjective Dimensions of language learning. Paper presented at the conference on Unity and Diversity in language use, University of Reading.

[33] Kuroda,Y. \& Suzuki,T. (1991). Arab students and English: The role of implicit culture. Behaviormetrika. 29. 23-44.

[34] Lambert, W.E. (1955). Measurement of the linguistic dominance of bilinguals. Journal of Abnormal and social Psychology, 50, 197- 200.

[35] Lamb,M. (2004). Integrative motivation in a globalizing world. System, 32 (1). pp. 3-19.

[36] Livingstone, L. (2004). The challenge of changing audiences. European Journal of Communication. 19(1), 75-86.

[37] Markwardt, A. H. (1948). Motives for the study of modern languages. Language Learning, 1, 1-11.

[38] Masgoret,A. \& Gardner, R. (2003). Attitudes, Motivation, and second language learning: A meta-analysis of studies conducted by Gardner and associates. Language Learning, 53(1), 2003, 123-163.

[39] McGroarty,M. (2001). Situating Second Language Motivation. In: Z. Dornyei, and R. W. Schmidt, (Eds.), Motivation and Second Language Acquisition. Honolulu, University of Hawai'i. pp. 69-91.

[40] Mowrer, O. H. (1950). Learning theory, and personality dynamics. New York: Ronald.

[41] Mueller, T.H. (1971). Student attitudes in the basic French course at the University of Kentucky. Modern language Journal 55, 290-8.

[42] Mueller, T.H. \& Miller, R.I. (1970). A study of students attitudes and motivation in a French course using programmed language instruction. International review of Applied Linguistics, 8/4, 297-320.

[43] Nida, E. A. (1956). Motivation in second language learning. Language learning, 7, 11-16.

[44] Obeidat, M. M. (2005). Attitudes and Motivation in second Language learning. Journal of Faculty of Education. 18(22), 62-82.

[45] Pintrich, P. R., Smith, D. A., Garcia, T., \& McKeachie, W.J. (1991). A manual for the use of the motivated strategies for learning questionnaire (MSLQ). Ann Arbor, MI: The Regents of the University of Michigan.

[46] Piquemal,N., \& Renaud, R. (2006). University students' beliefs and attitudes regarding Foreign language learning in France. TESL Canada Journal. Vol.24, 1, 67-78, Winter 2006.

[47] Sapir, E. (1921). Language: an introduction to the study of speech. Cambridge University press UK.

[48] Schumann, J. H. (2001). Appraisal psychology, neurobiology, and language. Annual Review of Applied Linguistics, 21, $23-42$.

[49] Sjoholm, K. (2000). Attitudes towards English and two national languages in Finland. In K. Sj oholm and A. østern (eds), Perspectives on Language and Communication in Multilingual Education.

[50] Spolsky, B. (1969). Attitudinal aspects of second language learning. Language learning 19, 271-283.

[51] Wenden, A. (1991). Learner Strategies for Learner Autonomy. Cambridge: Prentice Hall international.

[52] Yashima, T.(2002). Willingness to communicate in a second language: The Japanese EFL Context. Modern Language Journal, $86,54-66$.

Ranwa Khorsheed was born in Damascus 1984. She received her MA in Linguistics in 2014. She is currently a lecturer at the Arab international University and the Syrian Virtual University. She is interested in cognitive and corpus linguistics. She is a sworn Translator. She has published several papers on language teaching and co-authored a book on academic writing and research. 